\title{
La acción de secuestro prendario en el marco de relaciones de consumo ${ }^{1}$
}

\author{
The action of kidnapping within the framework \\ of consumer relations
}

A ação de seqüestro de penbor no âmbito de relações de consumo

L'action d'enlévement en raison d'une gage, dans le cadre des relations avec des consommateurs 在消费者关系框架内扣押质押的行动

Ezequiel Rodrigo Galván² y Gustavo Daniel Lueiro Campos $^{3}$
Universidad Nacional de La Plata - Argentina

Revista Derechos en Acción ISSN 2525-1678/ e-ISSN 2525-1686

Año 5/No 14, Verano 2019-2020 (21 diciembre a 20 marzo), 289-301

DOI: https://doi.org/10.24215/25251678e361

ORCID: https://orcid.org/0000-0003-0833-4366

Recibido: 01/01/2020

Aprobado: 03/03/2020

Resumen: Se analiza la procedencia de la acción de secuestro (art. 39 Ley 12.962) en el marco de relaciones de consumo y la compatibilidad de su carácter inaudita parte (sin derecho de defensa del consumidor ejecutado) con el régimen constitucional y de orden público protectorio

\footnotetext{
1 Ponencia presentada en “XXX Jornadas Académicas de la Comisión de la Abogacía Joven del Colegio de Abogados de la Provincia de Buenos Aires", 18 y 19 de octubre de 2019, Colegio de Abogados de San Isidro.

2 Abogado, escribano y procurador (UNLP). Maestría en Derechos Humanos (tesis pendiente) cohorte 2017-2018 (UNLP). Consultor (diseño de legislación tuitiva del consumo) Cámara de Diputados de la Nación. Agosto 2018 a la fecha. Coordinador y Profesor del Seminario de Derecho Bancario (UNLP).
}

3 Abogado (UNLP). Maestrando en Derecho Empresario (UA). Mail lueirocampos@gmail.com 
de usuarios y consumidores, recuperando los estándares establecidos en la jurisprudencia de la Suprema Corte de Provincia de Buenos Aires y de la Corte Suprema de Justicia de la Nación como directrices interpretativas.

Palabras clave: secuestro; derecho del consumidor

Abstract: The origin of the action of kidnapping (art. 39 Law 12962) in the framework of consumer relations and the compatibility of its inaudita parte character (without the right of defense of the executed consumer) with the constitutional and public order regime protecting users and consumers is analyzed, recovering the standards established in the jurisprudence of the Supreme Court of the Province of Buenos Aires and the Supreme Court of Justice of the Nation as interpretative guidelines.

Keywords: kidnapping; consumer rights

Resumo: É analisado a origem da ação de seqüestro (art. 39 da Lei 12.962) no contexto das relações de consumo e da compatibilidade de seu caráter de inédita parte (sem direito de defesa do consumidor executado) com o regime constitucional e de ordem pública protetor de usuários e consumidores, recuperando os padrões estabelecidos na jurisprudência do Supremo Tribunal da Província de Buenos Aires e do Supremo Tribunal de Justiça da Nação como diretrizes interpretativas.

Palavras-chave: seqüestro; direito do consumidor.

Résumé: On analyse la provenance de l'action de l'article 39 de la loi 12.962 dans le cadre des relations de consommation, et la compatibilité de ses caractéristiques -comme absence de droit de défense pour le consommateur- avec le régime constitutionnel et de protection de l'ordre public des utilisateurs et consommateurs; en recouvrant les principes établis dans la jurisprudence de la Cour suprême de Buenos Aires et de la Cour suprême de justice de la nation comme des lignes d'interprétation.

Mots-clés: enlèvement; droit de la consommation

摘要: 分析了绑架行为的根源 (第12.962号法律第39条), 涉及了消费 者关系, 以及其闻所未闻的部分 (未执行消费者的辩护权) 与宪法和 公共秩序保护制度的相容性。用户和消费者，恢复了布宜诺斯艾利 斯省最高法院和国家最高法院判例中确立的标准, 作为解释性指南。

关键词: 绑架, 消费者法 


\section{Introducción}

El presente trabajo tiene por objeto abordar la procedencia de la acción de secuestro prendario establecida en el artículo 39 de la Ley 12.962 en el marco de relaciones de consumo, la interacción entre las formas procesales y la plena vigencia del orden público protectorio de los consumidores, así como las respuestas jurisdiccionales existentes en el ámbito de la Provincia de Buenos Aires. En este aspecto, la legislación especial de prenda con Registro (Ley 12.962) reconoce a determinados acreedores acceso a una acción inaudita parte tendiente a desapoderar al deudor del bien prendado, sin bilateralidad y con una venta extrajudicial, lo cual se presenta prima facie como incompatible con las disposiciones del régimen protectorio (constitucional y de orden público) de usuarios y consumidores.

Ante esta contradicción, se reconstruyen los estándares desarrollados por la Suprema Corte de la Provincia de Buenos Aires y la Corte Suprema de Justicia de la Nación respecto de los procesos de cobro en el marco de relaciones de consumo y la articulación del derecho privado ante el estatuto del consumidor, así como la jurisprudencia de las Cámaras departamentales, a efectos de poder entender los términos en los cuales se debe abordar estos procesos en el marco de relaciones de consumo.

\section{Análisis}

El régimen de la prenda con registro, regulado por la Ley 12.962 (ratificado con la sanción del Código Civil y Comercial) introduce la acción de secuestro (art. 39) que concede a las entidades financieras el acceso una vía de cobro calificada por el desapoderamiento del bien en el marco de un proceso inaudita parte, con una asimilación de dichas entidades (privadas) al propio Estado. Con un diseño que privilegia el carácter expeditivo el cobro (sancionado durante la interrupción del estado democrático y constitucional Decreto-Ley $\left.N^{o} 15.348 / 46\right)$, este proceso de ejecución especial coexiste desde la última reforma 
constitución (1994) con el reconocimiento constitucional del derecho de los usuarios y consumidores, en el marco de la relación de consumo, a la protección de su seguridad, la protección de sus intereses económicos, y a condiciones de trato digno y equitativo, estableciendo la obligación de las autoridades tutelar su vigencia, así como de la restante legislación protectoria dictada por el Congreso de la Nación, cuyo rasgo distintivo es su carácter de orden público (arts. 3 y 65 Ley 24.240).

En este aspecto, la existencia de un proceso que permite al proveedor ejecutar su crédito inaudita parte, privando al consumidor del bien prendado sin derecho de defensa (relegándolo a una etapa posterior), y con un desapoderamiento intempestivo (el consumidor toma conocimiento en el acto de desapoderamiento) se presenta como contradictorio a las disposiciones del régimen protectorio derivado del artículo 42 de la Constitución Nacional. Sin embargo, ante esta contradicción parte de la doctrina y jurisprudencia ha sostenido el carácter inaplicable de las disposiciones de la Ley 24.240 a la acción de secuestro (ej. Cámara Civil y Comercial La Matanza Sala I c.5040/1 "Rombo Compañía Financiera S.A. c/ Ruiz Fuentes Juana s/ acción de secuestro (art.39 ley 12962)", sent. 13-III-2018) invocando el carácter de legislación especial y particular naturaleza de la acción (no jurisdiccional), en una interpretación que establece la primacía de la ley especial por sobre el orden público y constitucional, interpretación que cede progresivamente ante una más receptiva del mandato constitucional.

Como cuestión preliminar, se destaca que la existencia de una acción inaudita parte como la presente no excluye que las partes se encuentren vinculadas por una relación de consumo, la cual lleva incita la vigencia del orden protectorio por imperativo constitucional (Hernández \& Picasso, 2009). Así mismo, este régimen tiene su fundamento en la asimetría que existe entre las partes en el marco de las relaciones de consumo (Rusconi, 2015), así como en un interés activo del Estado la vigencia el orden público protectorio en cuestión (ej. 
intervención obligatoria del Ministerio Público como fiscal de ley: art. 52 Ley 24.240 y art. 27 Ley 13.133).

Se destaca en este sentido el fallo "Cuevas, Eduardo Alberto c/ Salcedo, Alejandro René s/ cobro ejecutivo" (S.C.B.A. C.109.305, sent. 01-IX-2010), que introduce como doctrina legal el carácter imperativo del artículo 36 "in fine" de la Ley 24.240 en los procesos ejecutivos promovidos en el marco de una relación de consumo. En este aspecto, la Suprema Corte establece como estándar la procedencia de un conocimiento causal (limitado) que marca un quiebre con uno de los paradigmas del derecho comercial, la "abstracción del título", en pos de la vigencia del orden público protectorio de los usuarios y consumidores.

Expresa la Suprema Corte (doctrina legal) "2. (...) Entiendo que frente a este tipo de dilema, debe imperar un criterio hermenéutico que permita arribar a la solución que proteja del modo más eficiente posible la finalidad tuitiva de grupos tradicionalmente postergados y particularmente vulnerables (...) la ley 24.240 consiste en la debida tutela del consumidor o el usuario, que a modo de "purificador legal" integra sus normas con las de todo el orden jurídico, de manera que se impone una interpretación que no produzca un conflicto internormativo, ni malogre o controvierta los derechos y garantías que, en tal sentido, consagra el art. 42 de la Constitución Nacional (...) Es por ello que, en lo que respecta al sub judice, debe intentarse una congruencia entre el sistema de protección establecido en la ley de defensa del consumidor y las disposiciones adjetivas que impiden en el ámbito de los procesos de ejecución la discusión de aspectos causales de la obligación. (...) considero que si bien impera en el ámbito de las relaciones de financiación para consumo, las limitaciones cognoscitivas propias de los procesos de ejecución, que impiden debatir aspectos ajenos al título (conf. art. 542, C.P.C.C.), es posible una interpretación de la regla aludida acorde con los principios derivados de la legislación de protección de usuarios (arts. 1, 2, 36 y 37, ley 24.240). (...)”.

Como se observa, la Suprema Corte establece como principio el respeto del orden público protectorio de usuarios y 
consumidores a partir de la integración de las reglas procesales y sustantivas de los procesos de cobro (ej. indagación causal con limitación probatoria), el cual, se proyecta en la restante jurisprudencia. De igual modo, la Corte Suprema de Justicia de la Nación recepta este criterio posteriormente ("Compañía Financiera Argentina S.A. c. Monzón, Mariela Claudia s/ ejecutivo" sent. 10-XII-2013), calificado por su carácter de interprete último y auténtico del texto constitucional.

El estándar establecido en esta jurisprudencia fundante es recuperado en el marco de las acciones de secuestro bajo análisis, con una remisión expresa a lo expresado en el marco de procesos ejecutivos: "Este Tribunal resolvió, en el citado precedente "Cuevas", que los jueces se encuentran autorizados a declarar de oficio la incompetencia territorial a partir de la constatación (mediante elementos serios y adecuadamente justificados) de la existencia de una relación de consumo a las que se refiere el art. 36 de la ley 24.240 (...) ante conflictos vinculados a operatorias de financiaciones destinadas al consumo las reglas generales de atribución de competencia establecidas en el ordenamiento ritual deben ceder frente a la normativa sustancial, en tanto no se ajusten a lo dispuesto por el citado artículo 36; resultando, por lo demás, "irrenunciables" los derechos de los consumidores en la medida en que el rango tuitivo que dimana de dicho contexto normativo tiene correlato en el texto del articulo 42 de la Constitución Nacional y de nada valdría protegerlos mediante una previsión microsistémica expresa si se pudiera admitir pacto o convenciones de cualquier rango que los distorsionaran" (S.C.B.A. C.120.068 "Fiat Crédito Financiera S.A. c/ Pilarczik, Mauricio Bruno s/ acción de secuestro" sent. 28-IX-2016).

Ante esta circunstancia, si bien los tribunales inferiores receptaron el carácter imperativo de la Ley de Defensa del Consumidor en materia de competencia, en la práctica no existió igual recepción de las defensas que se fundaban en la insuficiencia del título según la normativa protectorio de usuarios y consumidores (ej. Cámara Civil y Comercial de Junín "Naldo 
Lombardi S.A. c/ Caporale, Sergio Daniel s/ cobro ejecutivo" sent. 29-X-2013), estableciendo (de facto) la existencia del orden público (imperativo) del artículo 36 in fine de la Ley 24.240 y el restante orden público protectorio sin vigencia en el marco de los mismos procesos ejecutorios. Cabe destacar que la Ley 24.240 y la restante normativa que integra el estatuto del consumidor (ej. Ley 25.065) es de orden público y sin jerarquías internas, resultando plenamente aplicable el estándar establecido por la Suprema Corte en "Cuevas" (cit.) en los aspectos sustanciales del conflicto, criterio receptado por distintas Cámaras departamentales (ej. Cámara Civil y Comercial de Azul Plenario "HSBC Bank Argentina c/ Pardo Cristian Daniel s/ Cobro Ejecutivo" sent. 09-III-2017; Cámara Civil y Comercial de Quilmes Sala I "Banco Santander S.A. c/ Bustamante Emmanuel s/ cobro ejecutivo", entre otros).

Siendo que la aplicación de la normativa protectoria de los usuarios y consumidores como defensa sustantiva era materia controvertida, se presenta como quiebre (además de la decisión por su publicidad) respecto de la procedencia de acciones de secuestro en el marco de relaciones de consumo la sentencia dictada en la causa "Fiat Crédito Cia Financiera S.A. c/ De Natale Cesar Leandro s/ acción de secuestro (art. 39 ley 12962)" (Cámara Civil y Comercial de Junín sent. 02-II-2017), que rechaza la acción y establece que "Tal posibilidad conferida al proveedor, resulta lesiva del trato digno y equitativo al consumidor o usuario en la relación de consumo, previsto en los artículos 8 bis de la ley 24240 y 42 de la Constitución Nacional. Por lo tanto, por medio de una interpretación armonizante de las normas bajo examen, se llega a la inaplicabilidad del procedimiento previsto en el artículo 39 del decreto-ley 15348, a las relaciones de consumo" (con disidencia minoritaria).

Desde este precedente, encontramos que esta interpretación se replica en otras Cámaras departamentales, así como en los dictámenes del Ministerio Público Nacional (Cámara Civil y Comercial de Mar del Plata Sala III "Rancitelli Maximiliano Gabriel c/ Industrial And Commercial Bank Of China 
(Argentina) S.A. s/ medidas cautelares (traba/levantamiento)" sent. 31-X-2017, voto Jueza Zampini), recuperándose la centralidad derecho de defensa de los usuarios y consumidores en el marco de la relación de consumo: "(...) adelanto mi criterio en cuanto a que considero que el trámite normado por el art. 39 no puede ser aplicado a las relaciones de consumo en tanto impide el ejercicio del derecho constitucional de defensa en juicio del consumidor, parte débil en el contrato principal, al cual accede la prenda como garantía de cumplimiento. La solución propuesta encuentra su respaldo legal en el art. 42 CN y lo dispuesto por el art. 1094 CCCN el cual dispone que en caso de duda sobre la interpretación del CCCN o las leyes especiales, prevalece la más favorable al consumidor." (Cámara Civil y Comercial de Azul Sala I "Banco Santander Rio S.A. c/ Ver Florencia Paola s/ acción de secuestro" sent. 30-IV-2019), y "por medio de una interpretación armonizante de las normas bajo examen, se llega a la inaplicabilidad, por su incompatibilidad con el artículo 42 de la Constitución Nacional, del procedimiento previsto en el artículo 39 del decreto-ley 15.348 ratificado por la ley 12.962, a las relaciones de consumo." (Cámara Civil y Comercial de Quilmes Sala I "Banco Interfinanzas S.A. c/ Acevedo Carlos Alberto y otra s/Acción de secuestro (art.39 ley 12.962)", sent. 27-VIII-2019).

Este reconocimiento progresivo de las Cámaras del carácter imperativo de la totalidad del orden público protectorio dentro de los procesos de cobro (bajo los estándares establecidos en "Cuevas" cit.) se confirma por la Suprema Corte al manifestarse a favor de la integración del título que no abastece los requisitos sustantivos del artículo 36 de la Ley 24.240 (S.C.B.A. "Asociación Mutual Asís contra Cubilla, María Ester. Cobro ejecutivo", sent. 14-VIII-2019), destacándose el apartamiento de su doctrina que establece la improcedencia del recurso extraordinario por no ser sentencia definitiva, equiparable o de imposible reparación ulterior (ante la posibilidad de un proceso de conocimiento posterior) e ingresa a resolver el fondo del recurso interpuesto por el Ministerio Público. 
Como primer aspecto, si bien el objeto del recurso comprendía si el incumplimiento de los requisitos del artículo 36 de la Ley 24.240 implicaba la improcedencia de la vía intentada o su intimación a integrar el título (principio de congruencia), la Suprema Corte reconoce la procedencia de este conocimiento causal limitado en el marco procesos de cobro ejecutivo a todo el orden público protectorio al convalidar la intimación a integrar el título (como preparación de la vía), resolviendo el fondo cuando correspondía el rechazo del recurso de inaplicabilidad de ley interpuesto.

Así mismo, la decisión de la Suprema Corte recupera el estándar establecido en "Cuevas" (conocimiento limitado), estableciendo que constatada la relación de consumo se impone el cumplimiento del artículo 36 de la Ley 24.240, o demás normativa protectoria (ej. Ley 25.065, arts. 1380, 1381, 1388 y 1389 C.C.C.N.) por sobre las disposiciones sustantivas de los títulos valores, bajo un análisis que se circunscribe al contenido del propio título y la documental que integre el título (ej. contrato de préstamo). Se destaca que la Suprema Corte recupera la jurisprudencia de las distintas Cámaras departamentales con sus diferentes criterios y respecto de aquellas interpretaciones que sostienen la autonomía y completitud del título, expresa que "IV.4.a. (...) el criterio tradicional sobre los títulos de crédito en general y en las notas de abstracción, autonomía y completitud que caracterizan al pagaré (...) considera que en casos como el de autos el juez no tiene un mayor grado de injerencia que el previsto para cualquier cobro ejecutivo de esta clase de papeles de comercio. Se privilegia la idea de favorecer la cobrabilidad expeditiva de las obligaciones consignadas en estos papeles de comercio, como su circulación. Objetivamente, esta comprensión del asunto desconoce la aplicabilidad de la LDC."

Continúa el máximo tribunal provincial reconociendo la necesidad de una doctrina legal que brinde seguridad jurídica, y "IV.5.a Vigorizado en función de su consagración legal y constitucional, el derecho del consumo ba venido a trasformar diversos aspectos de las relaciones jurídicas, en particular las 
regidas por el derecho privado, dando lugar a adecuaciones $y$ reacomodamientos de normas e institutos (...) IV.5.d. En ese plano de congruencia sistemática es claro que la aplicabilidad de la LDC flexibiliza el andamiaje por el que discurre la pretensión ejecutiva, con respeto de los principios de bilateralidad $y$ defensa en juicio (arts. 18, Const. nac.; 15, Const. prov.; 34 inc. 5 apdo. "c" y 36 inc. 2 y concs., CPCC). (...) Si el título en cuestión, integrado de tal modo o bien autónomamente, satisface las exigencias legales prescriptas en el estatuto del consumidor, podrá dar curso a la ejecución. Ello, claro está, sin desmedro del derecho del ejecutado de articular defensas, incluso centradas en el mencionado art. 36, tendientes a neutralizar la procedencia de la acción.", así como establece la procedencia de la acción original con las adecuaciones necesarias para resultar compatible con el estatuto del consumidor.

Se recupera este pronunciamiento de la Suprema Corte debido a que establecen estándares que resultan aplicables a la acción de secuestro, principalmente la necesidad de adecuación y reordenamiento de las normas e institutos (ley 12.962) bajo el derecho protectorio de usuarios y consumidores, así como la procedencia de este derecho de orden público como defensa (aun cuando no se contemple procesalmente). En este aspecto, siendo que una acción que desapodera al consumidor sin derecho de defensa se presenta incompatible con el artículo 42 de la Constitución Nacional y normativa derivada (jurisprudencia citada), la adecuación implica introducir una instancia de defensa del ejecutado en la acción de secuestro y no "de manera tardía y probablemente ilusoria en el juicio ordinario posterior" (S.C.B.A. "Asociación Mutual Asís" cit.).

Así también se destaca que la Corte Suprema de Justicia de la Nación se pronunció recientemente en el marco de una causa de acción de secuestro o "secuestro prendario" ("HSBC Bank Argentina S.A. c/ Martínez, Ramón Vicente s/ secuestro prendario" sent. 11-VI-2019) haciendo lugar a la queja planteada por el Ministerio Público, ordenando a la Cámara Nacional Comercial que resuelva los planteos sustantivos respecto de la 
improcedencia de un proceso inaudita parte en el marco de relaciones de consumo. En este aspecto, si bien la sentencia no resuelve la cuestión de fondo, se aparta de su doctrina que establece la improcedencia del remedio federal contra una resolución que no representa una sentencia definitiva o equiparable (voto en disidencia Dr. Rosenkrantz y Dra. Highton de Nolasco) entendiendo que "En efecto, privar al deudor -en la relación de consumo- de todo ejercicio de derecho de defensa, en forma previa al secuestro del bien prendado, podría colocarlo en una situación que no se condice con la especial protección que le confiere el artículo 42 de la Constitución Nacional." (con remisión a este fallo en quejas posteriores).

Como se puede observar, en los últimos años las instancias de superiores de excepción (Suprema Corte y Corte Suprema) de modo progresivo han desarrollado interpretaciones del derecho privado que sostienen la vigencia y el carácter imperativo del régimen protectorio de usuarios y consumidores, cuya aplicación en todo proceso (independientemente de las formas procesales) se presenta actualmente como indiscutible (ej. incluso en un proceso inaudita parte actúa el Ministerio Público como fiscal de ley). Así mismo, las posiciones que sostienen la ajenidad de la acción de secuestro a esta normativa y sus consecuencias, actualmente pierden sustento ante el reconocimiento de su carácter jurisdiccional (S.C.B.A. "Fiat Crédito Financiera S.A." cit.), reafirmado por su tratamiento respecto de la decisión jurisdiccional mediante recurso extraordinario (C.S.J.N. "HSBC Bank Argentina S.A." cit.), así como por el reconocimiento del carácter transversal del contenido del artículo 42 de la Constitución Nacional y normativa derivada.

Ante esta circunstancia, una cuestión posterior a reconocer la adecuación de la acción de secuestro al estatuto del consumidor está dada por los términos de esa integración y adecuación normativa, especialmente cuando el estándar de la Corte ("Asociación Mutual Asís" cit.) establece que procede modo restringido al respeto del orden público comprometido (incorporar el derecho de defensa en este caso). De este modo, del 
rechazo de la acción (Fiat Crédito c/ De Natale" cit.), encontramos actualmente una reconducción del proceso a una ejecución prendaria ("Banco Santander c/ Ver Florencia Paola"; "Banco Interfinanzas S.A." cit.), que se presenta como una posible interpretación receptiva del estándar de la Suprema Corte en tanto es un proceso de ejecución bilateral (derecho de defensa) con limitaciones de conocimiento y defensa que ceden solo ante la indagación causal de la relación de consumo y cumplimiento de los requisitos sustantivos que el orden público protectorio de usuarios y consumidores impone (art. 36 Ley 24.240 y demás normativa aplicable).

\section{Conclusión}

A modo de conclusión, el reconocimiento constitucional y legal (como orden público protectorio) del derecho de usuarios y consumidores se presenta en muchos aspectos como contradictorio a los principios que rigen el derecho comercial y cambiario (celeridad en el cobro, autonomía de la voluntad, limitación del derecho de defensa y bilateralidad, abstracción de la causa, etc.), ante lo cual se impone la necesidad de integración y adecuación de las normas e institutos del derecho privado a las disposiciones de este régimen protectorio. Así mismo, se destaca el accionar e interpretación de las instancias superiores (Suprema Corte y Corte Suprema) que progresivamente reafirma la plena vigencia del derecho de los usuarios y consumidores en el marco de todo proceso jurisdiccional, aun cuando formalmente no permitan una indagación causal, generando estándares que brindan seguridad jurídica a las partes comprometidas y permiten generar uniformidad en las instancias inferiores.

En este aspecto, el reconocimiento de una acción de cobro inaudita parte (art. 39 Ley 12.962) se presenta como incompatible del derecho de defensa de usuarios y consumidores, correspondiendo adecuar la normativa a un proceso que permita una instancia de defensa del ejecutado, especialmente la 
derivada de las normas sustantivas del estatuto del consumidor (ej. art. 36 Ley 24.240). Siendo el estándar actual de la Suprema Corte una adecuación limitada a los aspectos incompatibles y la subsistencia de la acción, la reconducción de la acción como una ejecución prendaria se presenta como una solución en apariencia compatible: derecho de defensa en el marco de un proceso de ejecución sumaria.

\section{Bibliografía}

Hernández, C. A. \& Picasso, S. (2009) "La conexidad entre las relaciones de consumo" en "Ley de Defensa del Consumidor Comentada y Anotada” Tomo II, editorial La Ley, pp. 498-499.

Rusconi, D. (2015) "Fuentes Legales de la Protección del Consumidor" en "Manual de Derecho del Consumidor", editorial AbeledoPerrot, pp. 72-76. 